\title{
Jornal como fonte e/ou objeto da escrita histórica: proposta metodológica aplicada à análise das representações sobre "o político" na "grande imprensa carioca" de 1955 a 1960
}

\author{
Newspaper as object of historical writing: methodological proposal \\ applied to the analysis of the representations about "the political" \\ in the "great carioca press" from 1955 to 1960
}

Letícia Sabina Wermeier Krilow ${ }^{1}$

\begin{abstract}
Resumo: este trabalho faz breves considerações metodológicas sobre o uso da imprensa, especialmente do jornal, como fonte e/ou objeto de estudos históricos. Tal proposta se justifica ao se considerar a carência de uma sistematização acerca dos diferentes tipos de precauções que devem ser tomadas ao se utilizar os jornais em distintas pesquisas. Dessa forma, o trabalho está dividido em quatro partes, iniciando com uma abordagem mais descritiva, onde alguns dos principais cuidados metodológicos, de caráter pré-textual, foram sintetizados. Em um segundo momento, tem-se um tratamento mais prático, onde é apresentada uma metodologia que dê conta de atender as demandas do nível pré-textual. Sendo que, essa metodologia foi desenvolvida a partir de um estudo de caso, mais especificamente, para a pesquisa que objetiva analisar as representações sobre “o político", nas páginas dos jornais Jornal do Brasil, Correio da Manhã, Última Hora e O Globo, no período de 1955 a 1960. Já no terceiro momento, são elencados alguns apontamentos relacionados ao caráter textual da utilização dos periódicos na escrita histórica. Por fim, se encerra o artigo com a exposição de metodologias que dão conta da formação de um corpus documental de análise baseado em textos jornalísticos. Salienta-se que tais metodologias também foram desenvolvidas para o estudo de caso acima referido.
\end{abstract}

Palavras-chave: Jornais. Proposta metodológica. Escrita histórica.

Abstract: this paper makes brief methodological considerations about the use of the press, especially the newspaper, as a source and/or object of historical studies. This proposal is justified when considering the lack of a systematization about the different types of precautions that must be taken when using the newspapers in different researches. Thus, the work is divided into four parts, we will start with a more descriptive approach, where some of the main methodological care, of a pre-textual nature, were synthesized. In a second moment, a more practical treatment is presented, where a methodology is presented that addresses the demands of the pre-textual level. Since this methodology was developed from a case study, more specifically, for research that aims to analyze the representations about the political, on the pages of newspapers Jornal do Brasil, Correio da Manhã, Última Hora and O Globo in the period from 1955 to 1960. Already in the third moment, some notes related to the textual character of the use of the periodicals in historical writing were listed. Finally, the article ends

1 Mestre em História pela Pontifícia Universidade Católica do Rio Grande do Sul (PUCRS). Doutoranda em História na Pontifícia Universidade Católica do Rio Grande do Sul (PUCRS), Porto Alegre, RS, Brasil. http://orcid.org/0000-0002-7620-3598. E-mail: leticia. krilow@acad.pucrs.br 
with an exposition of methodologies that account for the formation of a documentary corpus of analysis based on journalistic texts. Emphasizing that such methodologies have also been developed for the above case study.

Keywords: Newspapers. Methodological proposal. Historical writing.

\section{Introdução}

A historiografia especializada no estudo da imprensa argumenta que, até a década de 1970, existia uma relutância em utilizá-la como fonte e objeto na escrita da história ${ }^{2}$. Assim, os poucos trabalhos que se dedicavam à análise da imprensa, se limitavam a fazer uma "história da imprensa”. Entretanto, esse aspecto não foi uma singularidade do caso brasileiro, mas estava inscrito em uma conjuntura mais ampla, do século XIX e início do XX, marcada pela predominância de uma historiografia associada ao ideal da busca pela verdade dos fatos ${ }^{3}$. Dentro dessa perspectiva, "os jornais pareciam pouco adequados para a recuperação do passado”, uma vez que "forneciam imagens parciais, distorcidas e subjetivas" (LUCA, 2005, p. 112).

Esse contexto passou a ser alterado no início da década de 1930 com a emergência da "Escola dos Annales”, entretanto, ainda foi necessário um longo percurso até se chegar à abundante utilização dos periódicos na produção do saber histórico ${ }^{4}$. Foi preciso esperar até a ascensão da terceira geração dos Annales, e a consolidação da sua proposta de utilização de "novos objetos, problemas e abordagens", para que os jornais deixassem de ser simples elementos auxiliares ${ }^{5}$. Por isso, não se pode deslocar a forma como a imprensa é concebida no fazer historiográfico da própria trajetória dessa, no campo do saber histórico.

No caso específico do Brasil, os primeiros trabalhos que utilizaram a imprensa como fonte datam do início da década de $1960^{6}$, mas os periódicos ainda eram vistos com suspeição, porém já não se questionava o uso do jornal em função de sua falta de objetividade, mas buscava-se "alertar para o uso instrumental e ingênuo que tomava os periódicos como meros receptáculos de informações a serem selecionadas, extraídas e utilizadas ao bel prazer do pesquisador" (LUCA, 2005, p. 116). Assim, Tânia de Luca argumenta que "o estatuto da imprensa sofreu deslocamento fundamental ainda na década de 1970: ao lado da História da imprensa e por meio da imprensa, o próprio jornal tornou-se objeto da pesquisa histórica” (LUCA, 2005, p. 118, grifos da autora).

\footnotetext{
2 Podem ser citados os trabalhos de LUCA (2005) e KARAWEJCZYK (2010).

3 O exemplo máximo dessa forma de se escrever história é a chamada Escola Metódica. Para um panorama geral das diferentes correntes historiográficas ver o clássico: BOURDÉ; MARTIN (1990).

4 Ver especialmente BURKE (1991) e REIS (2000).

5 Ver principalmente, LE GOFF; NORA (1976).

6 Tânia de Luca cita o trabalho de Jean Glénisson, Iniciação aos estudos históricos (1961); na terceira edição de Teoria da História no Brasil (1968) de José Honório Rodrigues, existem apenas dois parágrafos dedicados à História da imprensa, mesmo o jornal sendo uma de suas principais fontes.

7 Neste último, Luca cita a dissertação de mestrado de Maria Helena Capelato e Maria Ligia Prado (1974). A partir da análise dos editoriais (1927-1937) do jornal O Estado de S. Paulo, "as autoras evidenciaram a atuação do matutino como porta voz dos interesses de setores da classe dominante paulista e a maleabilidade do liberalismo abraçado pelos seus responsáveis” (LUCA, 2005, p. 118).
} 
Entretanto, as pesquisas iniciais nesse sentido ainda estão marcadas pela concepção de que a imprensa é uma "instância subordinada às classes dominantes, mera caixa de ressonância de valores, interesses e discursos ideológicos" (LUCA, 2005, p. 116) ${ }^{8}$. Abordagem que se tornou recorrente em muitas pesquisas históricas que utilizam esses meios de comunicação, mas, que simplificavam demasiadamente a compreensão do papel social dos impressos. Aliado a esse fator, tem-se a dificuldade em se trabalhar com a imprensa, decorrente da ausência de algum manual metodológico sistematizado que dê conta da utilização desses impressos como fonte e/ou objeto da pesquisa histórica. Neste sentido, propõe-se esboçar alguns princípios e possibilidades, a partir de diversos textos que indicam alguns cuidados metodológicos ao se usar especificamente o jornal como fonte ou objeto de pesquisa ${ }^{9}$, além de expor uma proposta metodológica aplicada a um estudo de caso. Dentro desta proposta, faremos breves observações sobre cada tópico, assim, sempre que possível, indicaremos alguns textos, onde as questões apontadas poderão ser aprofundadas.

\section{Cuidados metodológicos pré-textuais: conhecer os jornais}

Uma das primeiras tarefas é a preparação pré-textual, aqui estabelecida como, o processo onde se adquire o maior conhecimento possível sobre os impressos, neste caso específico, os jornais ${ }^{10}$. Para tanto, reuniu-se as orientações encontradas nos textos já citados de Maria Helena Capelato (1988) e Tânia de Luca (2005) e na mais recente publicação de Luis Martins (2018). De forma sintetizada os autores apontam para a necessidade de:

a) Pesquisa bibliográfica (pesquisas e textos teóricos) para justificar o trabalho ou para perceber se o assunto já foi suficientemente, e, bem trabalhado.

b) Localizar as publicações na história da imprensa. Esse é, segundo Tânia de Luca, a primeira tarefa e passo essencial para as pesquisas com fontes periódicas, pois "o conteúdo em si não pode ser dissociado do lugar ocupado pela publicação na história da imprensa" (LUCA, 2005, p. 142). Tal dissociação não pode ser efetivada pois, primeiramente, os impressos são dependentes das técnicas e equipamentos disponíveis e acessíveis em cada período histórico ${ }^{11}$. Em segundo lugar, não se pode perder de vista

\footnotetext{
8 Neste caso tem-se os estudos tornados clássicos de Nelson Werneck SODRÉ (2011), publicado originalmente em 1966 e Juarez Bahia (1990), publicado pela primeira vez em 1964. Já a ênfase na condição da imprensa como instrumento político pode ser exemplificada pelos trabalhos de GOLDENSTEIN (1987), RIBEIRO (2002) e, por fim, é a base da argumentação de LAURENZA (1998).

9 As indicações aqui expostas cabem tanto para a imprensa como fonte de informação histórica, como para a imprensa como objeto de pesquisa histórica, mas precisa-se frisar que cada uma dessas duas formas de se trabalhar com a imprensa possui suas especificidades e não devem ser consideradas como sinônimos.

${ }_{10}$ Considera-se pertinente a separação dos cuidados metodológicos em dois níveis: os pré-textuais e os textuais. Neste sentido, a concepção o nível pré-textual engloba uma série de elementos que necessitam ser considerados antes que se analise os textos jornalísticos propriamente. Já o nível textual se refere aos cuidados metodológicos que precisam ser tomados ao se examinar os textos retirados dos jornais.

${ }^{11}$ Sobre a relevância da técnica, dos equipamentos de produção e do suporte do texto ver BURKE (2003), CHARTIER (2001).
} 
que a "notícia” é uma construção social, assim, ela também é transformada conforme a época de análise ${ }^{12}$.

c) Considerar o contexto histórico em que os impressos estão inseridos. Nesse item, deve-se ponderar sobre a conjuntura social, política, cultural e econômica do período em que os impressos estudados estão inseridos.

d) Identificar a linha editorial do jornal e/ou seu histórico de tomadas de posições passadas, tanto em relação a grupos políticos e econômicos quanto às "bandeiras" de luta e doutrinas sustentadas.

e) Observar a periodicidade de publicação (diária, semanal, quinzenal etc.), pois tempos distintos de produção levam a formas distintas de apresentação e abordagem do conteúdo. Considerar, também, a regularidade e a durabilidade do impresso, refletindo sobre as causas de sua longevidade ou efemeridade.

f) Identificar o(s) proprietário(s) do jornal. É fundamental que se reconheça quem são os donos do jornal que serão utilizados, pois mesmo que não se trabalhe com a perspectiva - clássica, mas muito simplista - da determinação exclusiva dos conteúdos jornalísticos pelos seus proprietários, não se pode negar que tais agentes interferem em maior ou menor grau na forma e nos conteúdos publicados, dependendo de cada situação (jornal; tempo; espaço).

g) Fazer um mapeamento dos seus principais jornalistas, repórteres, editores, enfim, da equipe que trabalha no periódico. Essa pesquisa também é importante, pois são esses agentes que transformam os "acontecimentos" em "notícias". Dessa forma, nada mais pertinente do que compreender quem forma a equipe fixa/assídua do jornal ${ }^{13}$, uma vez que as visões de mundo de cada agente desse grupo também interferem no conteúdo e no modo de apresentação das publicações jornalísticas.

h) Estabelecer quais os vínculos ou compromissos externos, especialmente com grupos políticos e econômicos e instituições públicas e privadas, tanto dos proprietários e/ou responsáveis pelo jornal, quanto dos jornalistas, editorialistas, repórteres etc. Esse tópico é fundamental, tendo em vista os apontamentos dos itens "b" e "d".

i) Mapear as principais fontes de receita dos periódicos, que podem ser: venda avulsa, pelas assinaturas, classificados, publicidade privada e estatal, empréstimos privados e estatais etc. A relevância de se apreender as formas de financiamento dos periódicos está relacionada com o estabelecimento do grau de autonomia dos jornais em relação às pressões externas. Segundo Bourdieu, retomado por Luis Martins, quanto maior a autonomia financeira de um periódico, maior será o grau de autonomia deste em

${ }^{12}$ Sobre a perspectiva que considera a notícia como uma construção social ver: SCHUDSON (2010); CHARAUDEAU (2013); ALSINA (1989); TRAQUINA (2008); KUNCZIK (2003).

13 Para mais informações sobre esta classificação ver: KRILOW, 2018, p. 32. 
relação às pressões de anunciantes. Sua autonomia aumenta quanto mais o diário puder se financiar a partir de vendas avulsas e assinaturas, diminuindo ao passo em que depende da publicidade e, "neste último caso, o grau de dependência aumenta quanto mais esta publicidade vier dos poderes públicos e, no caso do financiamento privado, quanto maior for a concentração dos anunciantes" (MARTINS, 2018, p. 65). De qualquer forma, não se deve cair em um determinismo simplista, que vê na base material a única ou mais forte explicação para as tomadas de posições dos periódicos ${ }^{14}$.

j) Identificar o público preferencial do jornal. Segundo Martins, o público de um jornal pode ser segmentado em dois tipos, o leitor implícito, “construído no texto jornalístico que transparece nas marcas sociais do discurso (linguagem empregada, temas mais destacados)"15 e o leitor efetivo do jornal, "aquele que realmente compra ou lê, que podemos conhecer por indicadores externos, como índices de circulação, listas de assinantes, etc." (MARTINS, 2018, p. 66).

k) Assenhorar-se da forma de estruturação e divisão do conteúdo. Esse elemento é relevante, pois a própria forma de organização dos conteúdos no interior do periódico é um modo de hierarquização e valorização, assim, podendo indicar visões de mundo.

1) Caracterizar o material iconográfico presente, atentando para as opções estéticas e funções cumpridas por ele na publicação.

m) Atentar para as características de ordem material, sua aparência física (formato, tipo de papel, qualidade da impressão, capa, presença/ausência de ilustrações e publicidade). Tânia de Luca ressalta que se deve valorizar a materialidade e o suporte dos impressos, pois esses nada têm de natural. Nesse sentido, "historicizar a fonte requer ter em conta, portanto, as condições técnicas de produção vigentes e a averiguação, dentre tudo que se dispunha, do que foi escolhido e por quê" (LUCA, 2005, p. 132).

n) Os elementos que confluem para o estabelecimento do lugar de fala, da legitimidade desses periódicos e a situação de fala, para que se possa identificar, no período a ser investigado, a relação existente entre os diversos "campos do saber" (BOURDIEU, 2002) e assim, compreender da melhor forma possível as tomadas de posição dos jornais fonte/objeto de estudo.

Após o apontamento de tais cuidado metodológicos de caráter pré-textual, importa questionar: como cumprir todos os requisitos acima referidos? Nos deteremos, então, a responder essa pergunta.

\footnotetext{
${ }_{14}$ Se for considerada apenas a base material como determinante das tomadas de posição dos periódicos, não se conseguirá compreender, por exemplo, "o fato de que o Estado, durante toda a primeira metade da década de 1950, foi um importante - se não o principal - investidor na estruturação material dos jornais (com empréstimos, isenções de taxas, facilitação na importação, subvenções etc.), e, mesmo assim, a maioria dos diários fez uma ostensiva oposição a Vargas, então presidente da República” (KRILOW, 2018, p. 46).

15 Em síntese, prever o leitor indica mover o texto de modo a criar este leitor. Umberto Eco aponta diversos meios para construir esse leitor implícito, ou nos termos de Eco, o leitor-modelo: a) escolha de uma língua (excluindo quem não a fala); b) escolha de um tipo de enciclopédia ("se começo um texto com 'como está claramente explicado na primeira Crítica..." já reduzi, e bastante e corporativamente, a imagem do meu Leitor-Modelo); c) escolha de um dado patrimônio lexical e estilístico; d) escolha de sinais de gênero ("Queridas crianças, era uma vez..."); e) restringir o campo geográfico (“Amigos, romanos, concidadãos”); (ECO, 2002, p. 40).
} 
Para atender às demandas dos itens "a" ao "c" são indispensáveis pesquisas bibliográficas (livros, teses, dissertações, artigos, verbetes etc.) mais focadas nos aspectos históricos.

Já para tratar dos itens "d" ao "n”, são necessárias leituras bibliográficas que se referem aos jornais selecionados para trabalho. Mas, é preciso considerar que, tal suporte bibliográfico é necessário, mas, por vezes, não suficiente. Nestes casos, precisa-se efetuar uma investigação empírica nos jornais escolhidos para serem utilizados na escrita histórica.

Neste momento, podem surgir muitas dúvidas de como proceder metodologicamente para que esta pesquisa empírica possua validade científica. Neste sentido, apresentaremos uma possibilidade metodológica para as análises que utilizam series mais longas. Esta proposta é pautada no processo de amostragem que é uma técnica de escolha de amostra(s) adequada(s) para averiguação de um todo.

Considerando que todo o processo pré-textual pode-se resumir em conhecer os jornais que serão utilizados, precisa-se analisar cada edição selecionada do jornal por completa, isto é, da primeira à última página. Mas, certamente não se lerá, na íntegra, todos os periódicos da época que abarca o recorte temporal da investigação, por isso, indica-se a utilização da técnica da amostragem.

Como referido no resumo deste artigo, a aplicação dos cuidados metodológicos descritos anteriormente ocorrerá no estudo que objetiva analisar as representações sobre "o político", nas páginas dos periódicos Jornal do Brasil, Correio da Manhã, Última Hora e O Globo, no período de 1955 a $1960^{16}$.

Assim, o primeiro passo é verificar qual o número médio de edições publicadas anualmente pelo(s) jornal(is) fonte e/ou objeto de análise. Depois disso, é necessário definir qual o percentual do(s) jornal(is) que será analisado na integra (ex.: 20\%, 10\%, 5\% do total de edições anuais). Após o estabelecimento do valor da porcentagem, essa deve ser convertida em número de edições anuais.

O cálculo é efetuado por regra de três simples. Por exemplo, para o período de 1955 a 1960, a base de cálculo é de 305 publicações por ano ${ }^{17}$, dessa forma, 30\% dessas 305 edições equivalem a 91 edições; $25 \%$ a $76 ; 20 \%$ a $61 ; 15 \%$ a $45 ; 10 \%$ a $30 ; 4 \%$ a 12 .

$\mathrm{Na}$ pesquisa que objetiva analisar as representações sobre "o político", nas páginas de quatro jornais cariocas, em um período de seis anos (1955-1960), definiu-se que, nesta etapa pré-textual - conhecer os jornais -, seriam examinados $4 \%$ do total das edições anuais, isso corresponde a 12 diários por ano para cada jornal estudado, totalizando, no final dos seis anos 72 edições exploradas por completo para cada um dos quatro jornais (Jornal do Brasil, Correio da Manhã, Última Hora e O Globo).

Depois de estabelecido esse valor, o segundo passo é definir a forma como essas 12 edições (que correspondem aos $4 \%$ anuais) serão distribuídas ao longo de cada ano. No caso da pesquisa

16 Tal pesquisa é fruto da investigação que a autora deste artigo desenvolve em seu doutorado em História na PUCRS

17 Este valor é de 305 e não de 365 (dias do ano), pois, no período de 1955 - 1960, os periódicos possuíam apenas 6 edições semanais e não 7. 
anteriormente referida, escolheu-se uma edição por mês. O indicado é que a escolha seja mais neutra e dispersa possível, para tanto, optou-se por selecionar a sequência dos dias da semana.

Assim, como o estudo inicia em janeiro de 1955, se escolheu a primeira terça-feira do mês, em fevereiro a primeira quarta-feira do mês, em março a primeira quinta-feira do mês, em abril a primeira sexta-feira do mês, em maio o primeiro sábado do mês, em junho o primeiro domingo/segunda ${ }^{18}$ do mês, em julho se escolheu a segunda terça-feira do mês, em agosto a segunda quarta-feira do mês, em setembro a segunda quinta-feira do mês, e assim sucessivamente, até se chegar ao quarto domingo/segunda do mês de dezembro. Quando encerradas as quatro semanas do mês, (no caso do exemplo, quarto domingo/segunda de dezembro de 1956) optou-se por iniciar em 1957 pela quarta terça-feira do mês de janeiro, ao invés de começar, novamente, pela primeira terça-feira do mês, ou seja, o processo se deu de trás para frente, no intuito de deixar a amostragem o mais dispersa e neutra possível. Para facilitar a apreensão da proposta metodológica, olhar Quadro 1 “Distribuição das edições”.

\section{Quadro 1 - Distribuição das edições}

\begin{tabular}{|c|c|c|c|c|c|c|c|c|c|c|c|c|c|}
\hline \multirow{2}{*}{ Ano } & \multicolumn{12}{|c|}{ Meses } & \multirow{2}{*}{$\begin{array}{l}\text { Total } \\
\text { anual }\end{array}$} \\
\hline & Jan & Fev & Mar & Abr & Mai & Jun & Jul & Ag & Set & Out & Nov & Dez & \\
\hline 1955 & $\begin{array}{c}1^{\mathrm{a}} \\
\text { Ter }\end{array}$ & $\begin{array}{c}1^{\mathrm{a}} \\
\text { Qua }\end{array}$ & $\begin{array}{c}1^{\mathrm{a}} \\
\text { Qui }\end{array}$ & $\begin{array}{c}1^{\mathrm{a}} \\
\operatorname{Sex}\end{array}$ & $\begin{array}{c}1^{0} \\
\text { Sáb }\end{array}$ & $\begin{array}{c}1^{0} \\
D / S\end{array}$ & $\begin{array}{c}2^{\mathrm{a}} \\
\text { Ter }\end{array}$ & $\begin{array}{c}2^{\mathrm{a}} \\
\text { Qua }\end{array}$ & $\begin{array}{c}2^{\mathrm{a}} \\
\text { Qui }\end{array}$ & $\begin{array}{c}2^{\mathrm{a}} \\
\text { Sex }\end{array}$ & $\begin{array}{c}2^{\circ} \\
\text { Sáb }\end{array}$ & $\begin{array}{c}2^{\mathrm{o}} \\
\mathrm{D} / \mathrm{S}\end{array}$ & 12 \\
\hline 1956 & $\begin{array}{l}3^{\mathrm{a}} \\
\text { Ter }\end{array}$ & $\begin{array}{c}3^{\mathrm{a}} \\
\text { Qua }\end{array}$ & $\begin{array}{l}3^{\mathrm{a}} \\
\text { Qui }\end{array}$ & $\begin{array}{c}3^{\mathrm{a}} \\
\text { Sex }\end{array}$ & $\begin{array}{c}3^{0} \\
\text { Sáb }\end{array}$ & $\begin{array}{c}3^{0} \\
D / S\end{array}$ & $\begin{array}{c}4^{\mathrm{a}} \\
\text { Ter }\end{array}$ & $\begin{array}{c}4^{\mathrm{a}} \\
\text { Qua }\end{array}$ & $\begin{array}{c}4^{\mathrm{a}} \\
\text { Qui }\end{array}$ & $\begin{array}{c}4^{\mathrm{a}} \\
\text { Sex }\end{array}$ & $\begin{array}{c}4^{\circ} \\
\text { Sáb }\end{array}$ & $\begin{array}{c}4^{\mathrm{o}} \\
\mathrm{D} / \mathrm{S}\end{array}$ & 12 \\
\hline 1957 & $\begin{array}{l}4^{\mathrm{a}} \\
\text { Ter }\end{array}$ & $\begin{array}{c}4^{\mathrm{a}} \\
\text { Qua }\end{array}$ & $\begin{array}{l}4^{\mathrm{a}} \\
\text { Qui }\end{array}$ & $\begin{array}{c}4^{\mathrm{a}} \\
\operatorname{Sex}\end{array}$ & $\begin{array}{l}4^{\circ} \\
\text { Sáb }\end{array}$ & $\begin{array}{c}4^{\mathrm{o}} \\
\mathrm{D} / \mathrm{S}\end{array}$ & $\begin{array}{l}3^{\mathrm{a}} \\
\text { Ter }\end{array}$ & $\begin{array}{c}3^{\mathrm{a}} \\
\text { Qua }\end{array}$ & $\begin{array}{l}3^{\mathrm{a}} \\
\text { Qui }\end{array}$ & $\begin{array}{c}3^{\mathrm{a}} \\
\text { Sex }\end{array}$ & $\begin{array}{c}3^{\circ} \\
\text { Sáb }\end{array}$ & $\begin{array}{c}3^{\mathrm{o}} \\
\mathrm{D} / \mathrm{S}\end{array}$ & 12 \\
\hline 1958 & $\begin{array}{l}2^{\mathrm{a}} \\
\text { Ter }\end{array}$ & $\begin{array}{c}2^{\mathrm{a}} \\
\text { Qua }\end{array}$ & $\begin{array}{c}2^{\mathrm{a}} \\
\text { Qui }\end{array}$ & $\begin{array}{c}2^{\mathrm{a}} \\
\text { Sex }\end{array}$ & $\begin{array}{c}2^{\circ} \\
\text { Sáb }\end{array}$ & $\begin{array}{c}2^{\mathrm{o}} \\
\mathrm{D} / \mathrm{S}\end{array}$ & $\begin{array}{c}1^{\mathrm{a}} \\
\text { Ter }\end{array}$ & $\begin{array}{c}1^{\mathrm{a}} \\
\text { Qua }\end{array}$ & $\begin{array}{c}1^{\mathrm{a}} \\
\text { Qui }\end{array}$ & $\begin{array}{c}1^{\mathrm{a}} \\
\text { Sex }\end{array}$ & $\begin{array}{c}1^{\circ} \\
\text { Sáb }\end{array}$ & $\begin{array}{c}1^{\mathrm{o}} \\
\mathrm{D} / \mathrm{S}\end{array}$ & 12 \\
\hline 1959 & $\begin{array}{c}1^{\mathrm{a}} \\
\text { Ter }\end{array}$ & $\begin{array}{c}1^{\mathrm{a}} \\
\text { Qua }\end{array}$ & $\begin{array}{c}1^{\mathrm{a}} \\
\text { Qui }\end{array}$ & $\begin{array}{c}1^{\mathrm{a}} \\
\text { Sex }\end{array}$ & $\begin{array}{c}1^{0} \\
\text { Sáb }\end{array}$ & $\begin{array}{c}1^{\mathrm{o}} \\
\mathrm{D} / \mathrm{S}\end{array}$ & $\begin{array}{l}2^{\mathrm{a}} \\
\text { Ter }\end{array}$ & $\begin{array}{c}2^{\mathrm{a}} \\
\text { Qua }\end{array}$ & $\begin{array}{c}2^{\mathrm{a}} \\
\text { Qui }\end{array}$ & $\begin{array}{c}2^{\mathrm{a}} \\
\text { Sex }\end{array}$ & $\begin{array}{c}2^{\circ} \\
\text { Sáb }\end{array}$ & $\begin{array}{c}2^{\mathrm{o}} \\
\mathrm{D} / \mathrm{S}\end{array}$ & 12 \\
\hline 1960 & $\begin{array}{l}3^{\mathrm{a}} \\
\text { Ter }\end{array}$ & $\begin{array}{c}3^{\mathrm{a}} \\
\text { Qua }\end{array}$ & $\begin{array}{l}3^{\mathrm{a}} \\
\text { Qui }\end{array}$ & $\begin{array}{c}3^{\mathrm{a}} \\
\text { Sex }\end{array}$ & $\begin{array}{l}3^{0} \\
\text { Sáb }\end{array}$ & $\begin{array}{c}3^{\mathrm{o}} \\
\mathrm{D} / \mathrm{S}\end{array}$ & $\begin{array}{l}4^{\mathrm{a}} \\
\text { Ter }\end{array}$ & $\begin{array}{c}4^{\mathrm{a}} \\
\text { Qua }\end{array}$ & $\begin{array}{l}4^{\mathrm{a}} \\
\text { Qui }\end{array}$ & $\begin{array}{c}4^{\mathrm{a}} \\
\operatorname{Sex}\end{array}$ & $\begin{array}{c}4^{\circ} \\
\text { Sáb }\end{array}$ & $\begin{array}{c}4^{\mathrm{o}} \\
\mathrm{D} / \mathrm{S}\end{array}$ & 12 \\
\hline \multicolumn{13}{|c|}{ Total dos 6 anos } & 72 \\
\hline
\end{tabular}

Fonte: Elaboração própria.

Após a definição dessas etapas, se efetuará um exame por completo de cada jornal selecionado, o que leva ao terceiro passo, isto é, a elaboração de um quadro onde serão colocadas as informações relevantes para aprofundar o conhecimento sobre o diário analisado. Esse quadro

\footnotetext{
18 Neste caso colocou-se o domingo e a segunda juntos, pois o Jornal do Brasil e o Correio da Manhã não possuem a edição de segunda-feira e $O$ Globo e Última Hora não possuem a edição de domingo. Assim, juntado os dois dias da semana para que não ocorra uma defasagem na amostragem.
} 
é bem dinâmico e pode ser adequado às necessidades de cada pesquisador. Como exemplo, segue, o Quadro 2, elaborada para dar conta de "conhecer os jornais".

\section{Quadro 2 - Coleta de informações sobre os jornais}

\begin{tabular}{|c|c|c|c|c|c|c|c|}
\hline \multicolumn{3}{|c|}{ Jornal: ULTLLA HORA } & \multicolumn{2}{|c|}{ Data: Terça feura, 0401/1955 } & \multicolumn{3}{|c|}{ Paginas: 16} \\
\hline \multicolumn{8}{|c|}{$\begin{array}{c}\text { Valor } 2 \text { eruzeiros } \\
\text { Diretor Responsivel: Danten Coelho Diret }\end{array}$} \\
\hline Pág. & Tirulos & A etoria texto & Tipo & Assuates & Sintese da pg. & Tevoografia & Publicidade \\
\hline $\begin{array}{l}\text { Noda } \\
\text { pigins }\end{array}$ & $\begin{array}{l}\text { Inserur os } \\
\text { tioulos dos } \\
\text { textos } \\
\text { existentes } \\
\text { nesta pizina }\end{array}$ & $\begin{array}{l}\text { Inserif o vome } \\
\text { de gaets } \\
\text { astinn o texto }\end{array}$ & $\begin{array}{l}\text { Noticis, } \\
\text { Columa } \\
\text { Editterial, } \\
\text { Artigo } \\
\text { Reportagems } \\
\text { etc. }\end{array}$ & $\begin{array}{l}\text { Assunto a que } \\
\text { se refere o texto }\end{array}$ & $\begin{array}{ll}\text { Sintere } & \text { dos } \\
\text { asyumtos } \\
\text { encontrabos na } \\
\text { piginn. }\end{array}$ & $\begin{array}{l}\text { Uma pequena } \\
\text { descriclo de } \\
\text { tods } \\
\text { iecesogratin }\end{array}$ & 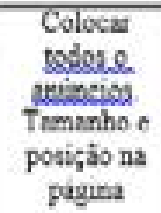 \\
\hline $\begin{array}{l}\text { Ex. } \\
\text { p.1 }\end{array}$ & 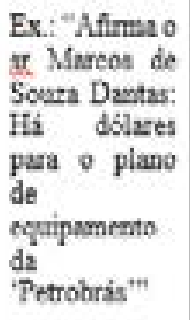 & $\begin{array}{l}\text { Ex: untor nibo } \\
\text { referenciado }\end{array}$ & Ex: Noticia & $\begin{array}{l}\text { Ex: Nocional - } \\
\text { Roliticha } \\
\text { sconconaca }\end{array}$ & $\begin{array}{l}\text { Ex. Assunton } \\
\text { gertis, mas } \\
\text { predominiacia de } \\
\text { temsas nacionais } \\
\text { soltados para a } \\
\text { economia }\end{array}$ & $\begin{array}{l}\text { Ex: Foto } \\
\text { Souga Divess } \\
\text { duscursasdo - } \\
\text { imagem cocos } \\
\text { cousplemento }\end{array}$ & $\begin{array}{c}\text { Ex:Sem } \\
\text { publieidade } \\
\text { na poumeira } \\
\text { pigiea }\end{array}$ \\
\hline $\begin{array}{l}\text { Ex } \\
\text { p2 }\end{array}$ & $\begin{array}{l}\text { Ex: "Dois } \\
\text { fatcos } \\
\text { positivos" }\end{array}$ & $\begin{array}{l}\text { Ex: } \\
\text { Demingos } \\
\text { Velasco }\end{array}$ & $\begin{array}{l}\text { Ex 1 } \\
\text { "Columa de } \\
\text { "O } \\
\text { Popular"' }\end{array}$ & $\begin{array}{l}\text { Ex: Noctonal. } \\
\text { politica }\end{array}$ & $\begin{array}{l}\text { Ex Asrunton } \\
\text { gerais, mas } \\
\text { predominincia de } \\
\text { temass nacionais } \\
\text { wollados para a } \\
\text { politica }\end{array}$ & $\begin{array}{l}\text { Ex-foto de } \\
\text { Domingos } \\
\text { Velasco- } \\
\text { marcaudo a } \\
\text { columa de tha } \\
\text { autoria }\end{array}$ & $\begin{array}{l}\text { Ex } \\
\text { Agencia } \\
\text { Cantelo } \\
\text { Cibsasil- } \\
\text { Cia de } \\
\text { fleanciam. } \\
\text { [CI].[P+] }\end{array}$ \\
\hline & & & & & & & \\
\hline
\end{tabular}

Fonte: Elaboração própria.

O quadro acima foi pensado com o intuito de abarcar o máximo de informações possíveis sobre o(s) jornal(is) fonte/objeto de pesquisa. No cabeçalho se inserem os dados básicos, como nome do jornal, data, número de páginas da edição, tiragem, proprietário, equipe de direção, elementos que contemplam os itens "E" e "F", elencados nos cuidados metodológicos pré-textuais. Logo abaixo, são inseridos os dados referentes aos textos jornalísticos, no primeiro item se registra o número da página, na sequência os títulos dos textos, seguido da autoria deste quando tiver. O tópico da autoria é extremamente relevante para que se identifique os principais jornalistas, articulistas, colunistas do jornal, salientando que, após a identificação destes, o ideal é que se faça uma pesquisa sobre tais agentes, contemplando os itens "g" e "h", acima referidos.

No tópico "tipo”, faz-se a classificação dos textos entre as diferentes formas de produção discursiva. Essa classificação é extremante necessária, pois cada tipo de escrito possui especificidades que devem ser consideradas. Por exemplo, o editorial é o espaço privilegiado, mas não único, de expressão do que deveria ser considerado o ponto de vista oficial do jornal e/ ou da redação, é um texto analítico que não possui assinatura (KRILOW, 2018, p. 31). 
As colunas ${ }^{19}$, são textos que podem ser assinados ou não, tratam de temas relacionados a alguma editoria ${ }^{20}$. Além disso, um elemento que vale ser destacado é que, em muitos casos, uma coluna pode acumular um grande capital de prestígio, a ponto de tornar-se uma referência do jornal. Já os artigos são textos opinativos, cujo conteúdo e opiniões emitidas são de responsabilidade exclusiva do(a) autor(a). Podem expressar argumentos convergentes e/ou

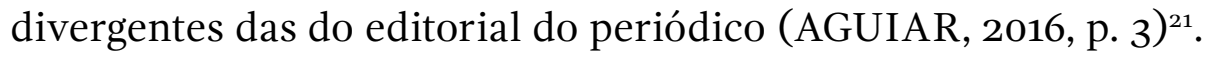

Por fim, as reportagens são matérias que possuem grande centimetragem em uma página. Diferentemente da notícia, que se constitui como a informação cotidiana que é dada pelos jornais de maneira mais compulsória, as reportagens são uma iniciativa da redação, possuem uma pauta prévia, que é elaborada a partir de "reuniões de pauta"22, onde o editor-chefe e os repórteres sugerem temas para que, então as matérias sejam produzidas (AGUIAR 2016, p. 4 ) $^{23}$.

Voltado para a descrição da tabela acima, no item "assunto" coloca-se de forma bem ampla o tema geral de cada texto, iniciando com a definição geoespacial (ex.: o assunto é de caráter local, regional, nacional, internacional) e depois a temática (ex.: política, economia, educação, saúde, esporte etc.). Essa classificação é necessária para que se preencha o próximo item da tabela: "síntese da página". Nesse tópico se evidenciará qual o assunto mais abordado na página em análise, e qual a forma de alocação dos escritos no interior do diário (início, meio, fim), assim, poderá se definir, a especificidade de organização interna do jornal (ex.; quais assuntos vão preferencialmente na capa, na página dois, onde são alocados os textos de política, economia, social etc., quais textos entram nas seções de política, cidade, policial, econômica etc.), contemplando, assim, o tópico "k" dos cuidados metodológicos.

Seguindo para o próximo item da tabela, chega-se na "iconografia". A análise do aspecto iconográfico é extremamente relevante, não apenas como uma estratégia estética, mas especialmente em razão da potencialidade política de suas várias expressões de linguagem, e, assim, abrange-se o item "l". Por fim, o mapeamento da publicidade que compreende aspectos importantes do tópico "I". Mas neste item, além de ser anotado o nome do produto ou da empresa que está anunciando no jornal, é relevante que se registre o tamanho do anúncio e a sua localização na página. Para simplificar a descrição desenvolveu-se algumas siglas (no caso do exemplo na tabela correspondem as siglas [CI] para a localização na página e [P+]

\footnotetext{
19 Em particular as colunas que não são assinadas, geralmente, tratam de temas ligados à editoria ou às seções onde são diagramadas, e, apresentam uma aproximação muito forte com as opiniões emitidas nos editoriais. Sendo os colunistas os autores das colunas.

20 Editoria é um setor especializado em áreas determinadas (esporte, polícia, arte, meio ambiente e etc.).

${ }^{21}$ Em alguns casos, os articulistas (autores dos artigos) se tornam referência do impresso e o público leitor passa a buscar essa opinião quando procura um diário específico. Ainda, não se pode esquecer que os articulistas mais antigos de um impresso e que fazem parte da equipe editorial do mesmo participam da elaboração e redação dos editoriais. Outra especificidade dos textos assinados é a questão do uso de pseudônimos. Nesses casos, muitas vezes pode ser uma estratégia utilizada por um jornalista, pelo editor-chefe e mesmo pelo dono do jornal para expor uma opinião sem se comprometer diretamente, uma vez que o texto está assinado.

${ }^{22}$ A pauta é uma ordem de serviço transmitida pelos chefes de reportagem. A pauta normalmente indica a pessoa que deve ser entrevistada, local, horário e até mesmo o tamanho da reportagem que deve ser produzida, também deve indicar os temas principais que devem ser abordados no texto.

${ }^{23}$ Assim, as reportagens são extremamente relevantes, pois indicam o esforço de mobilização do jornal para difundir algum assunto sob uma forma determinada pela pauta, transparecendo mais do que a notícia o seu enfoque sobre o referido tema.
} 
para o tamanho), que podem ser observadas no Quadro 3, "Siglas tamanho publicidade" “, e no Quadro 4 "Siglas Posição publicidade".

\section{Quadro 3 - Siglas tamanho publicidade}

Em um total de 9 colunas (largura), e aproximadamente 200 linhas (altura), os tamanhos dos anúncios são classificados seguindo os seguintes critérios

\begin{tabular}{|c|c|}
\hline 1 coluna e até 15 linhas $=[\mathrm{PP}]$ & 6 colunas e de 100 a $125=[\mathrm{M}+]$ \\
\hline 2 colunas e de 15 a 25 linhas $=[\mathrm{P}-]$ & 7 colunas e de 125 a $150=[\mathrm{G}]$ \\
\hline 3 colunas e de 25 a 50 linhas $=[\mathrm{P}]$ & 8 colunas e de 150 a $175=[\mathrm{G}+]$ \\
\hline 4 colunas e de 50 a 75 linhas $=[\mathbf{P}+]$ & De $75 \%$ a $90 \%$ da página $=[\mathrm{GG}]$ \\
\hline 5 colunas e de 75 a 100 linhas $=[\mathrm{M}]$ & $100 \%$ da página $=[\mathrm{GG}+]$ \\
\hline
\end{tabular}

Fonte: Elaboração própria.

Importa salientar que tais classificações têm a intenção de ser apenas a indicação de um caminho, uma dentre muitas possibilidades, podendo existir variantes, e, ocorrências que não se enquadram nas delimitações acima, nessas situações, pode-se criar outras categorias ou mesmo marcar observações.

\section{Quadro 4 - Siglas Posição publicidade}

\begin{tabular}{|l|l|l|}
\hline Esquerdo Superior [ES] & Centro Superior [CS] & Direito Superior [DS] \\
\hline Esquerdo Centro [EC] & Centro Centro [CC] & Direito Centro [DC] \\
\hline Esquerdo Inferior [EI] & Centro Inferior [CI] & Direito Inferior [DI] \\
\hline
\end{tabular}

Fonte: Elaboração própria. 
Essa divisão pode ser exemplificada na Imagem 1 "Divisão posições publicidade”.

\section{Imagem 1 - Divisão posições publicidade}

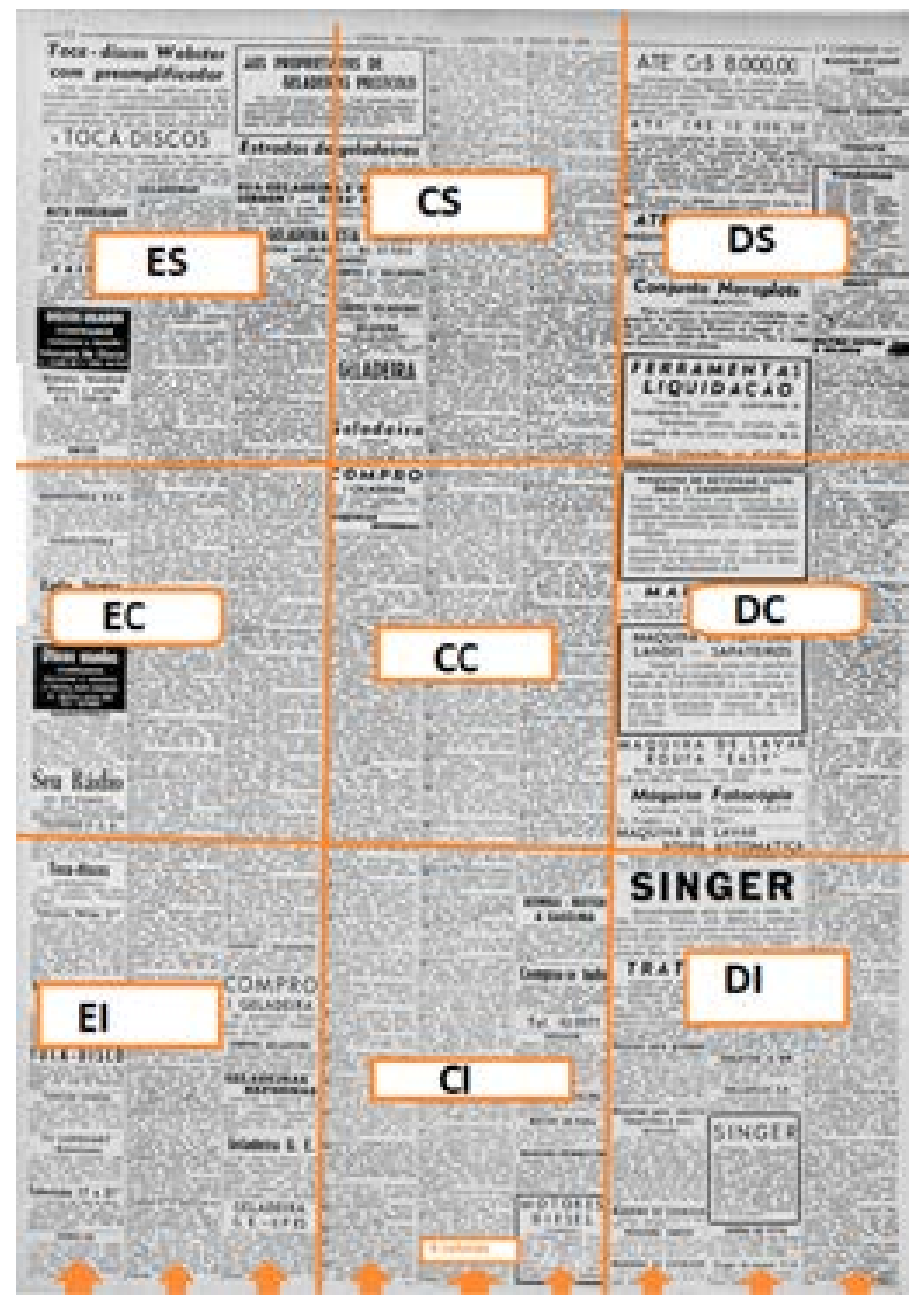

Fonte: Elaboração própria.

Entretanto, em relação ao tamanho da publicidade, podem ocorrer casos em que um anúncio ocupe diversos espaços (por exemplo: esquerdo, superior, centro e inferior, neste caso a sigla ficaria [ESCI]. Para a escrita da sigla é importante que se mantenha um padrão, por exemplo: começar pelo lado (esquerdo, centro ou direito) para depois vir a altura (superior, centro ou inferior). Caso uma publicidade pegue dois lados e duas alturas (ou mais), é só seguir a mesma regra. Pode-se ainda indicar que um ou vários anúncios cobrem a página inteira [PI].

Vale ressaltar que, tanto a classificação dos tamanhos e das posições efetuadas na publicidade podem ser aplicadas nos demais tipos de textos e imagens jornalísticas, pois ambos podem indicar a visibilidade ou não, o destaque ou não, que os editores do jornal deram ao assunto que está sendo trabalhado. Pois, o tamanho dos textos, imagens etc., evidenciam o 
espaço que o tema recebeu no jornal, já a localização indica a hierarquia dos textos, segundo o critério da "linha de leitura", ou seja, formando um "X" na página ${ }^{24}$.

Após a tabela preenchida pode-se, a partir de todas as características apreendidas, identificar o público referencial do jornal, abarcando assim, o item "J”. Por fim, o "lugar de fala", "situação de fala" e legitimidade do jornal frente ao público e aos pares, questões referentes ao tópico "n".

Certamente, quando os pesquisadores se deparam com a realidade da pesquisa histórica, percebem que nem sempre é possível conseguir todas as informações acima elencadas. Entretanto, é necessário esse empenho para que se monte um panorama das condições sociais e econômicas de produção jornalística, no período histórico investigado. De qualquer modo, precisa-se atentar para o fato de que o mapeamento das questões acima referidas é necessário, entretanto, não suficiente, pois elas não se esgotam na investigação. Dessa forma, inclui-se outro aspecto metodológico: os cuidados ao se analisar os textos jornalísticos.

\section{Cuidados metodológicos textuais: análise dos textos nos e dos jornais}

Sob esse aspecto, tomou-se por base outras bibliografias, das quais destaca-se o texto de Claudio Elmir (1995) e de Monica Karawejczyk (2010). Ambos são extremamente úteis, pois apontam que é preciso considerar que os historiadores constroem o seu "saber" a partir do saber de outrem, neste caso, do saber criado e difundido pelos textos jornalísticos. Dessa forma, precisa-se ponderar:

a) A necessidade de apreender a diferenciação existente entre o papel desempenhado pelo jornalista e o exercido pelo historiador (KARAWEJCZYK, 2010, p. 137-143).

b) A existência de um leitor diferenciado- ou seja, os historiadores, não são os leitores implícitos do jornal estudado, nem os leitores empíricos do período em que o diário circulava (ELMIR, 1995, p. 21) ${ }^{25}$.

c) Elemento diretamente relacionado com a concepção da existência de uma leitura diferenciada ("intensiva" e não "extensiva") - primeiro, faz-se uma "leitura flutuante" - o que o Elmir descreveu como "passar os olhos" e depois uma leitura intensiva, isto é, deve-se ler o jornal como historiadores e não como leitores comuns (ELMIR, 1995, p. 21-22).

d) Questão da recepção - dificilmente consegue-se estipular quais compreensões os leitores empíricos estabeleceram, assim, precisa-se cuidar para não imputar a esse leitor relações de sentido com o texto e com as ideias que ele próprio pode não ter estabelecido em suas leituras (ELMIR, 1995, p. 23).

\footnotetext{
${ }^{24}$ Segundo Rafael Silva, em decorrência da escrita ocidental da esquerda para a direita, no sentido horizontal, nossa "visão instintivamente se desloca com rapidez em diagonal para o lado inferior oposto" assim, "a rota básica da vista se projeta do lado superior esquerdo para o lado inferior direito" (SILVA, 1985, p. 47-48).

25 O que leva a distinção já mencionada entre o leitor implícito, ou leitor modelo (aquele projetado e, por vezes, criado pelo periódico) e o leitor-empírico (quem realmente lê, sendo que se pode ler de várias formas um texto).
} 
e) O que remete a questão do cuidado com o anacronismo - o pecado mortal dos historiadores, ou seja, cuidado para não “imputarem a autores e obras intenções e significados que jamais teriam, nem poderiam ter tido, em seus contextos originais de produção" (JASMIN; FERREZ, 2006, p. 27) ${ }^{26}$.

f) Existência de um tempo diferenciado - refere-se à defasagem entre a formulação do discurso inscrito no periódico em relação à nossa experiência de leitura.

Bem como são necessários outros cuidados importantes:

g) Análise do maior número, para assim estabelecer a distinção entre aquilo que é significativo para a compreensão do objeto, daquilo que pode ser descartado. Nesse sentido, não se deve tomar um enunciado isoladamente, pois esse, isoladamente, não oferece condições para que a sua adequada compreensão, além de poder não ser representativo do conjunto das tomadas de posição de um determinado impresso.

h) Não se deixar convencer facilmente pelo texto (deslumbramento), nem adotar uma desconfiança exagerada (ELMIR, 1995, p. 24), ou seja, cuidado para não interpretar os textos jornalísticos somente sob a perspectiva dualista do jornalismo ou como "espelho da realidade"27 ou como pura manipulação ${ }^{28}$. Disso decorre a necessidade de se buscar um referencial teórico alternativo a essa dicotomia.

i) Não transformar os textos-objeto de nossa análise em instrumentos de nossos pretextos, ou seja, cuidar para não buscar no texto comprovar ideias, teorias, concepções estabelecidas previamente à pesquisa (ELMIR, 1995, p. 24-25). Pois, os historiadores, segundo Luca, correm o risco de ir buscar em um periódico precisamente aquilo que pretendem confirmar, o que em geral acontece quando uma palavra, uma linha ou um texto inteiro é desvinculado de uma realidade (LUCA, 2005). Apontamento que retoma a ideia de que não se deve tomar um enunciado isoladamente.

j) Utilizar outras fontes, além dos jornais, mesmo que esse seja o objeto, justamente para conseguir justificar empiricamente suas afirmações (ELMIR, 1995, p. 25-26). Mais do que isso, a utilização de outras fontes é imprescindível para apreender com "quem" os jornais estudados estão dialogando, sua posição diante de seus interlocutores - o que remete, novamente, ao "lugar de fala".

k) Não olhar o texto apenas pelo texto. Para que se consiga apreender as tomadas de posições e interpretar os escritos das páginas dos jornais de modo mais complexo e

\footnotetext{
26 Ver RANCIÈRE (2011).

${ }_{27}$ A perspectiva do jornalismo como "espelho da realidade" foi construída pelos próprios jornalistas com objetivo de legitimar a sua profissão, neste sentido, sobre a “ideologia espontânea dos profissionais”, ver RODRIGUES (1993). Tal concepção já foi criticado especialmente, por TRAQUINA (2005, p. 28), MOUILLIAUD (1997), MOLOTCH; LESTER (1993, p. 38).

${ }_{28}$ O conceito de manipulação como pensado originalmente implica uma série de questões que torna o conceito, inaplicável, pois, essa teoria parte do princípio que é possível a um agente "conhecer" o real como ele é, e, tendo conhecimento total sobre o real, esse agente, manipula conscientemente os dados que coleta para construir uma nova realidade e, com isso, atender à objetivos específicos.
} 
dinâmico, é preciso conhecer a lógica da produção dos textos jornalísticos. Embora dificilmente se consiga recuperar o dia a dia da produção do jornal estudado, é indicado que se tenha uma noção mínima de como ocorre a transformação de um "acontecimento" em "notícia”"29. Para isso, é fundamental que se conheça as principais teorias da comunicação $0^{30}$, bem como, efetuar leituras sobre a lógica interna de produção jornalística ${ }^{31}$. Dentro dessa perspectiva, Bourdieu argumenta que "os jornalistas têm óculos especiais a partir dos quais veem certas coisas, e veem de certa maneira as coisas que veem", operam, assim "uma seleção e uma construção do que é selecionado" (BOURDIEU, 1997, p. 25). Estes óculos, segundo Darnton (1990) são moldados na sala de redação, no convívio dos jornalistas novos com os antigos, enfim, na atuação profissional. Os jornalistas, possuem ainda um linguajar próprio: o "jornalês".

Todas essas questões são relevantes, pois levam a questionar a validade da separação entre verdadeiro e falso. Neste sentido, argumenta-se que é mais válido compreender o texto jornalístico como um discurso sobre o social, e, a partir dessa perspectiva, identificar quais elementos, conceitos, ideias são mobilizadas, que visões de mundo podem ser identificadas, o que tal discurso pode dizer sobre a sociedade em que foi produzido. Dessa forma, Elmir (1995) usa o exemplo de Darnton para afirmar que "não existe uma rigidez nos discursos que se elaboram sobre o social”, por isso, também, seria pouco útil buscar uma coerência nos discursos (de um autor, jornal etc.), pois tal coerência praticamente não existe.

Para finalizar este bloco, é preciso que se aponte a necessidade da escolha de um referencial teórico e uma metodologia de análise adequados, especialmente para que não se reduza ou simplifique demasiadamente as interpretações sobre a fonte/objeto de estudo.

\section{Qualitativo e Quantitativo: apontamentos sobre possíveis metodologias de coleta de textos jornalísticos}

Quando observado com um pouco de cautela, percebe-se que, até o momento, existe um hiato entre o nível pré-textual e o nível textual, pois se efetuou um salto direto dos cuidados prévios à análise dos textos jornalísticos para as precauções que deveriam ser tomadas ao se examinar esses textos. Assim, há a ausência de uma explicitação metodológica de como formar o "corpus documental" inicial, e, é nisso que nos determos a partir de agora.

Assim, dentro do recorte temporal de cada pesquisa histórica pode-se selecionar e coletar os textos jornalísticos a partir dos critérios quantitativos e qualitativos. Ambas metodologias não são opostas, bem pelo contrário, muitas vezes são usadas como complementares. Iniciaremos com a abordagem do critério qualitativo.

\footnotetext{
29 Ver: Nelson Traquina (2005; 2008); SCHUDSON (2010); CHARAUDEAU (2013).

30 Sobre isso, ver: MATTELART (2006) e WOLF (2003).

31 Ver: TRAQUINA (1993; 2008); RODRIGO ALSINA (1989); MOUILLIAUD (2002); CHARAUDEAU (2013); BIRD, DARDENNE (1993); DARNTON (1990); BERGER (2002).
} 
O aspecto qualitativo se subdivide em basicamente duas modalidades:

a) Por roteiro de datas representativas de acontecimentos específicos. Nessa metodologia a seleção inicial dos textos jornalísticos que poderão ser analisados na pesquisa é feita com base em um roteiro de datas previamente estabelecido. A escolha deste roteiro ocorre com base em leituras pertinentes ao período/assunto, assim, o pesquisador parte do seu objetivo central e secundários para montar um roteiro com datas específicas, procurando nos jornais aquelas datas previamente estabelecidas.

Para conseguir um êxito maior na pesquisa, o ideal é fazer a procura - além do dia previamente estabelecido - em alguns dias antes e alguns dias depois dessa data. Pois, muitas vezes, por questões de horários e defasagem entre a saída de uma mensagem e a sua chegada a redação do jornal, os textos sobre o assunto não são publicados na data em que o acontecimento se efetuou. Ainda, quando o acontecimento é programado (como eleições presidenciais, visita de autoridades, exposições etc.) as publicações sobre o tema podem ocorrer antes do acontecimento em si e se estendem por alguns dias após o seu ocorrido. Já se for um acontecimento inesperado o mais recorrente é que se estenda os dias da pesquisa no pós-ocorrido, o que não impede que se procure indícios em dias anteriores.

Por exemplo, no caso da pesquisa que busca analisar as representações sobre "o político", nas páginas dos jornais Jornal do Brasil, Correio da Manhã, Última Hora e O Globo no período de 1955 a 1960 o roteiro de datas centra-se em 5 momentos específicos em que os textos sobre o político poderiam ser mais recorrentes: as eleições em 3 outubro de 1955, 1958 e 1960; a reforma eleitoral de 25 julho 1955; o Movimento de 11 de Novembro. Nestes casos, efetuou-se uma varredura intensiva, olhando todos os editoriais dos jornais publicados um mês antes e um mês depois de cada data mencionada, e, coletando todos os editoriais pertinentes ao objetivo central e específicos da pesquisa.

Nesse caso, observa-se que o roteiro foi montado após a delimitação de qual tipo de texto jornalístico será selecionado e analisado na pesquisa (apenas editoriais), tal delimitação é decorrente do fato de a pesquisa exemplo desse artigo, objetivar avaliar a "opinião oficial" de quatro jornais cariocas sobre "o político" no período de 1955-1960 (seis anos), por isso, o texto jornalístico escolhido para ser coletado e posteriormente analisado foi o editorial. A escolha previa facilita o trabalho, pois não se precisará procurar o tema de estudo no jornal inteiro, mas já se irá direcionado ao tipo de texto escolhido. Porém, isso não significa que não se possa escolher, a posteriori, os tipos de textos jornalísticos (editorial, colunas, reportagens, artigos, notícias etc.), pois, em alguns casos o tema de pesquisa não é suficientemente trabalhado em apenas um tipo de produção discursiva, nesse caso, o pesquisador escolherá quais tipos de textos irá trabalhar, mas sempre atentando para as especificidades de cada produção, pois, como já mencionado, as tomadas de posições não podem ser compreendidas da mesma 
forma. De modo geral, a escolha dos tipos de textos jornalísticos irá depender do objetivo da pesquisa e das perguntas que se quer responder ${ }^{32}$.

b) Por assuntos/temas/conceitos específicos. Nestes casos a busca é mais livre, no sentido de não ser centrada em datas, mas sim ao assunto e ao recorte temporal da pesquisa, assim, o pesquisador procurará no(s) jornal(is) escolhido(s) o assunto/ tema/conceito específico que deseja investigar. Sendo que, as mesmas observações, já mencionadas, sobre a escolha dos tipos de textos jornalísticos a serem utilizados, são válidas também para esse caso.

Essa metodologia encontrou nos acervos digitais um grande aliado, pois nessas plataformas (como a Hemeroteca Digital da Biblioteca Nacional) tem-se o item "busca por palavras”, onde são inseridas palavras-chave ou termos específicos ao assunto de pesquisa, e, tais palavras, quando reconhecidas pelo site, são grifadas nas páginas ${ }^{33}$. Uma dica valiosa é iniciar a pesquisa com uma palavra central (feminismo, por exemplo), após uma busca inicial, recolher alguns textos e fazer uma leitura destes, pois, a partir, desse exame podem surgir novas palavras e expressões chaves para a ampliação da pesquisa.

Passaremos agora, aos apontamentos sobre a metodologia de coleta de caráter quantitativo. Esse aspecto não será novo dentro deste artigo, pois o que embasa o método quantitativo é o critério de amostragem. Os passos são exatamente os mesmos aos já referidos - 1) verificar qual o número médio de edições publicadas anualmente pelo(s) jornal(is) fonte e/ou objeto; 1.1) definir qual o percentual do(s) jornal(is) que será analisado na integra; 1.2) converter essa porcentagem em número de edições anuais; 2) definir a forma como as edições serão distribuídas ao longo de cada ano; e 3) elaboração de uma tabela onde serão colocadas as informações sobre os textos encontrados através tanto da amostragem quanto do critério qualitativo.

Dessa forma, como já mencionado, a média de edições publicadas anualmente nesses seis anos do recorte temporal da pesquisa é de 305, assim, definiu-se que, seriam analisados $15 \%$ das publicações anuais (o que corresponde a 45 edições anuais). A distribuição dessas 45 edições ocorreu por semana, ou seja, foi selecionada uma edição por semana ao longo do ano, e, dessa edição apenas o texto editorial, e, dentro da metodologia, caso o editorial do dia escolhido tivesse pertinência, era coletado ${ }^{34}$. Para que a distribuição entre os dias da semana ficasse o mais dispersa possível, desenvolveu-se o seguinte esquema:

\footnotetext{
$3^{2}$ As opções mais comuns são: a) averiguar a "posição oficial" dos jornais sobre um tema/assunto/conceito, nestes casos utiliza-se, preferencialmente, mas não exclusivamente, os editoriais; b) comparar as tomadas de posições em diferentes tipos de textos jornalísticos (ex.: avaliar se as posições no editorial convergem ou divergem das posições das colunas, ou artigos); c) compreender como um tema/assunto/conceito foi abordado de modo geral em um periódico, o que torna necessário que se investigue o maior número possível de tipos textuais; d) por fim, são enriquecedoras as abordagens que buscam a comparação entre os diferentes jornais e dos jornais em relação a outros campos de saber.

33 Um elemento que gera críticas a esta metodologia se refere ao fato de em alguns casos o sistema não reconhecer a palavra ou expressão procurada, deixando passar elementos que poderiam ser importantes para pesquisa.

34 Como todos os jornais estudados nesta pesquisa (Jornal do Brasil, Correio da Manhã, Última Hora e O Globo) possuem acervo digital a coleta do texto editorial ocorre pelo programa "Pic-Pic", que permite a captura do texto selecionado na tela do computador (é semelhante a tecla "PrtSc SysRq"), após a coleta do texto o mesmo é salvo em arquivo JPG.
} 
Na primeira semana de 1955, escolheu-se a terça-feira, na segunda semana do ano a quarta-feira, na terceira semana do ano a quinta-feira, na quarta semana a sexta-feira, na quinta semana do ano o sábado, na sexta semana o domingo/segunda ${ }^{35}$, na sétima semana escolheu-se a terça-feira novamente, na oitava semana a quarta feira, e assim sucessivamente até finalizar as 45 semanas do ano de 1955. A escolha do dia da primeira semana de 1956 é o precedente ao que encerrou o ano de 1955, assim, se o dia da semana 45 do ano de 1955 for uma quinta-feira, a edição selecionada na primeira semana de 1956 será a sexta-feira.

Por fim, a elaboração do quadro. Nesta fase do método, tanto no critério quantitativo como no qualitativo será elaborado um quadro relativamente simples que, dá conta de abarcar as informações referentes aos textos que se encontram no dia selecionado. Para a pesquisa sobre o pensamento político dos jornais cariocas foi elaborado o Quadro 5.

\section{Quadro 5 - Mapeamentos editoriais}

\begin{tabular}{|c|c|c|c|}
\hline Semanas & $\begin{array}{l}\text { Dia da } \\
\text { semana }\end{array}$ & Título editorial / data / caderno / página & Assunto \\
\hline 1 & Terça & “A situação bancária”, Correio da Manhã, 4 de janeiro de 1955, $1^{\circ}$ C, p.6. & $\begin{array}{l}\text { ECO - inflação } \\
\text { POL-Econômica }\end{array}$ \\
\hline 2 & Quarta & $\begin{array}{l}\text { "A política do orçamento", Correio da Manhã, } 12 \text { de janeiro de } 1955 \text {, } \\
1^{\circ} \mathrm{C}, \text { p.6. }\end{array}$ & POL-Econômica \\
\hline 3 & Quinta & $\begin{array}{l}\text { "Normalidade e eleição", Correio da Manhã, } 20 \text { de janeiro de } 1955 \text {, } \\
1^{\circ} \mathrm{C} \text {, p.6. }\end{array}$ & POL \\
\hline 4 & Sexta & “A Voz do Brasil”, Correio da Manhã, 28 de janeiro de $1955,1^{\circ} \mathrm{C}$, p.6. & $\begin{array}{l}\text { POL - Vargas/C.F } \\
\text { Am-Democracia }\end{array}$ \\
\hline 5 & Sábado & $\begin{array}{l}\text { "A Câmara e o mausoléu”, Correio da Manhã, } 5 \text { de fevereiro de } 1955 \text {, } \\
1^{\circ} \mathrm{C}, \text { p.6 }\end{array}$ & $\begin{array}{l}\text { POL } \\
\text { Suces.Presid. }\end{array}$ \\
\hline 6 & $\begin{array}{l}\text { Domingo/ } \\
\text { segunda }\end{array}$ & $\begin{array}{l}\text { "O candidato e os equívocos", Correio da Manhã, } 13 \text { de fevereiro de } \\
1955,1^{\circ} \mathrm{C} \text {, p.6. }\end{array}$ & $\begin{array}{l}\text { POL } \\
\text { Suces.Presid. }\end{array}$ \\
\hline 7 & Terça & Edição não encontrada - 22 de fevereiro de 1955 & ---- \\
\hline 8 & Quarta & $\begin{array}{l}\text { “Apreensões patrióticas", Correio da Manhã, } 2 \text { de março de } 1955 \text {, } \\
1^{\circ} \mathrm{C}, \text { p. } 6 .\end{array}$ & $\begin{array}{l}\text { POL } \\
\text { Golpismo }\end{array}$ \\
\hline
\end{tabular}

Fonte: elaboração própria.

Neste quadro, pode-se observar que as semanas foram enumeradas na primeira coluna, ao lado, marcou-se o dia da semana, seguindo a sequência acima descrita (na primeira semana de 1955, escolheu-se a terça-feira, na segunda semana do ano a quarta-feira etc.). Na terceira coluna se inseriu o título do editorial do dia selecionada pela amostragem, independentemente de ser incorporado ou não ao corpus documental da pesquisa, sendo que a diferenciação entre

35 Ver nota 17. 
os textos considerados pertinentes ou não à pesquisa foi feita por cores, assim, os textos que possuem o título em preto não foram coletados, já os em vermelho, farão parte do "corpus documental" inicial da pesquisa ${ }^{36}$.

Sobre essa questão, importa destacar que tanto a metodologia qualitativa de roteiro por datas e quanto a quantitativa por amostragem irá trazer textos jornalísticos que não são pertinentes à pesquisa, mesmo assim, aconselha-se a anotar os títulos dos escritos que não são pertinentes, para posteriormente, poder-se estabelecer o grau de visibilidade que o(s) jornal(is) deram ao assunto que o pesquisador está trabalhando frente a outros temas, bem como, efetuar um mapeamento dos assuntos abordados no período de análise.

Por exemplo, a partir do quadro 5 pode-se constatar que de 7 edições encontradas, 5 são referentes ao assunto da pesquisa, ou seja, 71\% dos textos selecionados pela metodologia de amostragem são pertinentes ao objeto da investigação, o que indica um alto grau de visibilidade que esse periódico deu ao tema.

Ainda, percebe-se que na sétima semana, no dia selecionado (terça-feira, 22/02/1955) a edição não foi encontrada, neste caso, se especifica esta situação no quadro 5 e, não se muda a data, para que a amostragem não seja comprometida. Todas essas situações ocorrem também na pesquisa qualitativa por roteiro de datas. Já na qualitativa por assunto, isso não é tão recorrente, uma vez que o programa marca o termo de busca na página do periódico, mas também, podem ocorrer situações em que o termo foi marcado em um tipo de texto que não irá compor o corpus documental, ou mesmo, a abordagem do assunto não é pertinente ao objeto do pesquisador.

Após a finalização desses procedimentos, tem-se a composição de um "corpus documental" inicial, ainda não é o final. O próximo passo é justamente a delimitação do "corpus documental" que será efetivamente analisado profundamente na pesquisa. Neste momento, se volta para os textos selecionados através do critério quantitativo e/ou qualitativo e se define quais textos são realmente representativos e pertinentes aos objetivos da pesquisa, e, por fim, efetua-se a formação do "corpus documental” de análise.

A próxima etapa consiste na análise dos textos que compõe este "corpus documental" final, entretanto, como tal processo é complexo, requer uma abordagem em separado, a qual não será tratada neste artigo.

\section{Considerações finais}

Ao efetuarmos uma breve retomada sobre a relação história e imprensa no Brasil, apontou-se que desde os anos 1970 os impressos vêm ganhando espaço como fonte e/ou objeto da escrita histórica. Entretanto, constata-se que há grandes dificuldades para se trabalhar com a imprensa em virtude de algumas visões reducionistas que concebem a imprensa na dualidade

36 Relembrando que, como o objetivo da pesquisa é avaliar as representações sobre o político nos textos que possuem a "opinião oficial" dos jornais, os títulos inseridos nesta tabela são apenas dos editoriais. Assim, quando outros textos forem utilizados a ocorrência dos títulos será maior. 
de "espelho da realidade" ou como pura manipulação. Mas, especialmente, a dificuldade de se utilizar a imprensa na escrita histórica é decorrente da ausência de um manual metodológico sistematizado que dê conta da utilização desses impressos como fonte e/ou objeto da pesquisa.

Dessa forma, propor-se a elaboração de um “exercício”, no qual elencou-se alguns princípios e cuidados metodológicos na utilização da imprensa, especialmente, dos jornais como objetos/fontes para as pesquisas históricas, juntamente, com um viés mais prático de coleta de dados sobre os jornais e a formação de um "corpus documental” com textos jornalísticos.

\section{Referências}

ABREU, Alzira A.; LATTMAN-WELTMAN, Fernando. A Imprensa em Transição: O Jornalismo Brasileiro nos anos 50. Rio de Janeiro: Fundação Getúlio Vargas, 1996.

AGUIAR, Rafe. Dicionário Jornalístico: entenda todos os jargões. Coisas de Jornalista, 2016.

ALSINA, Miquel R. La construcción de la notícia. Paidós, Barcelona, 1989.

BAHIA, Juarez. Jornal, história e técnica. São Paulo: Ática, 1990.

BARBOSA, Marialva. "Cinquenta anos em cinco": Consolidando o mito da modernização (1950-1960). In: BARBOSA, Marialva. História cultural da imprensa: Brasil: 1990-2000. Rio de Janeiro: Maud X, 2007. p. 149-173.

BARDIN, Laurence. Análise de conteúdo. São Paulo: 70, 2011.

BIRD, ELIZABETH S.; DARDENNE, ROBERT W. Mito, registo e 'estórias': explorando as qualidades narrativas das notícias. In: TRAQUINA, Nelson (org.). Jornalismo: Questões, teorias e "estórias". Lisboa: Vega, 1993. p. 263-277.

BERGER, Cristha. Toda a notícia que couber, o leitor apreciar e o anunciante aprovar, a gente publica. In: MOUILLIAUD, M (org.) O Jornal: forma e sentido. Brasília: Paralelo 15, 2002. p. 715-726.

BOURDÉ, Guy; MARTIN, Hervé. As Escolas Históricas. Mem Martins (Portugal): Publicações Europa-América, 1990.

BOURDIEU, Pierre. Sobre a televisão. Rio de Janeiro: Jorge Zahar, 1997.

BOURDIEU, Pierre. A Distinção: crítica social do julgamento. Porto Alegre: Zouk, 2015a.

BOURDIEU, Pierre. A produção da crença: contribuições para uma economia dos bens simbólicos. Porto Alegre: Zouk, 2015b.

BOURDIEU, Pierre. O Poder Simbólico. Lisboa: Perspectiva, 1989.

BOURDIEU, Pierre. Esboço de Uma Teoria da Prática, Precedido de Três Estudos de Etnologia Cabila. Oeiras: Celta Editora, 2002.

BURKE, Peter. A Escola dos Annales. 1929-1989. São Paulo: Edit. Univ. Estadual Paulista, 1991.

BURKE, Peter. Uma História Social do Conhecimento: de Gutemberg a Diderot. Rio de Janeiro: Zahar, 2003.

CAPELATO, Maria Helena. Imprensa e História do Brasil. São Paulo: Contexto/Edusp, 1988. 
CHALABY, J. O Jornalismo como invenção anglo-americana: Comparação entre o desenvolvimento do jornalismo francês e anglo-americano (1830-1920). Media \& Jornalismo, [S. l.], n.3, p. 29-50, 2003.

CHARAUDEAU, Patrick. Discurso das Mídias. São Paulo: Contexto, 2013.

CHARTIER, R. (org.) Práticas de Leitura. Trad. Cristiane Nascimento. São Paulo: Estação Liberdade, 2001.

DARNTON, Robert. Jornalismo: toda notícia que couber, a gente publica. In: DARNTON, Robert. O Beijo de Lamourette: mídia, cultura e revolução. São Paulo: Cia das Letras, 1990, p. 41-57.

ECO, Umberto. Lector in fabula. A cooperação interpretativa no texto narrativo. Trad. Attilio Cancian, São Paulo, Perspectiva, 2002.

ELMIR, Cláudio Pereira. As armadilhas do jornal: algumas considerações metodológicas de seu uso para a pesquisa histórica. Cadernos do PPG em História da UFRGS, Porto Alegre, n.13, p. 19-29, dez. 1995.

GOLDENSTEIN, Gisela T. Do Jornalismo Político à Indústria Cultural. São Paulo: Summus, 1987.

JASMIN, Marcelo; FERREZ Jr., João. História dos Conceitos: dois momentos de um Encontro Intelectual. In: JASMIN, Marcelo Gantus; FERES JÚNIOR, J. (org.). História dos conceitos: debates e perspectivas. Rio de Janeiro: Edições Loyoloa; Editora PUC-Rio, 2006. https://doi. org/10.1590/s0102-69092005000100002

KARAWEJCZYK, Mônica. O Jornal como documento histórico: breves considerações. Historiae, Rio Grande, v.1, n.3, p. 131-147, 2010.

KRILOW, Letícia S. W. Cidades de Papel: as representações sobre as favelas na imprensa carioca durante o Segundo Governo Vargas (1951-1954). 2018. 220f. Dissertação (Mestrado em História), Pontifícia Universidade Católica do Rio Grande do Sul, Porto Alegre, 2018. https:// doi.org/10.5327/z2447-211520161600027

KUNCZIK, Michael. A Produção da Notícia. In: Conceitos de jornalismo. São Paulo: Summus, 2003, p. 219-275.

LAURENZA, Ana M. A. Lacerda X Wainer: o Corvo e o Bessarabiano. 2. ed. São Paulo: Ed. SENAC, 1998.

LE GOFF, J.; NORA, P. História: novos problemas, novas abordagens, novos objetos. Rio de Janeiro: Francisco Alves, 1976.

LUCA, Tania de. História dos, nos e por meio dos periódicos. In: PINSKY, Carla Bassanezi. Fontes Históricas. São Paulo: Contexto, 2005· p. 111-153. https://doi.org/10.5327/z2447-211520161600027

MARTINS, Luis Carlos dos Passos. História dos conceitos e conceitos na História: a imprensa como fonte/objeto da História Conceitual do Político. In: DOMINGOS, Charles Sidarta Machado; BATISTELLA, Alessandro; ANGELI, Douglas Souza (org.). Capítulos de História Política: fontes, objetos e abordagens. São Leopoldo: Oikos, 2018. E-book. p. 53-74. https://doi. org/10.33662/ctp.v9i1.10470

MATTELART, Armand. História das teorias da comunicação. 9. ed. São Paulo: Loyola, 2006. MOLOTCH, Harvey; LESTER, Marilyn. As notícias como procedimento institucional: acerca do uso estratégico de acontecimentos de rotina, acidentes e escândalos. In: TRAQUINA, Nelson. (org.). Jornalismo: questões, teorias e “estórias”. Lisboa: Vega, 1993. 
MORAES, Roque. Análise de Conteúdo. Revista Educação. Porto Alegre, ano XXII, n. 37, 1999. MOUILLIAUD, Maurice (org.) O Jornal: forma e sentido. Brasília: Paralelo 15, 2002.

RANCIÈRE, Jacques. O conceito de anacronismo e a verdade do historiador. Tradução Mônica Costa Netto. In: SALOMON, Marlon (org.). História, verdade e tempo. Chapecó: Argos, 2011. p. 21-50.

REIS, José Carlos. Escola dos Anais. A inovação em História. São Paulo: Paz e Terra, 2000.

RIBEIRO, Ana Paula Goulart. Imprensa e História no Rio de Janeiro dos anos 1950. Rio de Janeiro: E-papers, 2007.

RIBEIRO, Ana Paula Goulart. Clientelismo, corrupção e publicidade: como sobreviviam as empresas jornalísticas no Rio de Janeiro dos anos 1950? Ciberlegenda, Niterói, n. 8, [p. 1-15], 2002. https://doi.org/10.22409/c-legenda.voio8.26157

RIBEIRO, Ana Paula Goulart. Jornalismo, literatura e política: a modernização da imprensa carioca nos anos 1950. Estudos Históricos, Rio de Janeiro, n. 31, p. 147-160, 2003.

RIBEIRO, Lavina. Madeira. Imprensa e Espaço Público: A Institucionalização do Jornalismo no Brasil (1808-1964). Rio de Janeiro: E-Papers, 2004. https://doi.org/10.15603/2175-7755/ cs.v25n41p97-114

RODRIGUES, Adriano Dutra. O acontecimento. In: TRAQUINA, N. (org.). Jornalismo: questões, teorias e "estórias". Lisboa: Vega, 1993.

SILVA, Rafael Souza. Diagramação: o planejamento visual gráfico na comunicação impressa. São Paulo: Summus, 1985.

SODRÉ, Nelson Werneck. História da Imprensa no Brasil. São Paulo: INTERCOM; Porto Alegre: EDIPUCRS, 2011.

SCHUDSON, Michael. Descobrindo a Notícia: Uma história social dos jornais nos Estados Unidos. Petrópolis: Vozes, 2010.

TRAQUINA, Nelson. Teorias do Jornalismo I. 2. ed. Florianópolis: Insular, 2005.

TRAQUINA, Nelson. Teorias do Jornalismo II. 2. ed. Florianópolis: Insular, 2008.

TRAQUINA, Nelson. (org.). Jornalismo: questões, teorias e “estórias”. Lisboa: Vega, 1993.

WOLF, Mauro. Teoria das comunicações de massa. São Paulo: Martins Fontes, 2003.

Recebido em: 29/3/2019.

Aprovado em: 7/5/2019.

\section{Letícia Sabina Wermeier Krilow}

Instituição: Pontifícia Universidade Católica do Rio Grande do Sul

Endereço Postal: Av. Ipiranga, 6.681 - Partenon, Porto Alegre/RS

CEP: 90619-900 